\title{
O ENSINO INCLUSIVO NAS AULAS DE EDUCAÇÃO FÍSICA: ESTUDO A PARTIR DA PERCEPÇÃO DOS PROFESSORES
}

Valmor Ramos, Universidade do Estado de Santa Catarina - UDESC, Florianópolis, Santa Catarina - Brasil

Vinicius Zeilmann Brasil, Universidade Federal de Santa Catarina - UFSC, Florianópolis, Santa Catarina - Brasil

Thais Emanuelli da Silva de Barros, Universidade Federal de Santa Catarina - UFSC, Florianópolis, Santa Catarina-Brasil

Ciro Goda, Universidade do Estado de Santa Catarina - UDESC, Florianópolis, Santa Catarina - Brasil

Jonas Godtsfriedt, Universidade Federal de Santa Catarina - UFSC, Florianópolis, Santa Catarina - Brasil

\section{RESUMO}

O objetivo do estudo foi descrever as percepções de professores, a respeito das dificuldades para implementar o ensino inclusivo nas aulas regulares de Educação Física. Realizou-se um estudo de abordagem qualitativa com três professores de Educação Física escolar. Para a coleta dos dados utilizou-se um roteiro de entrevista estruturada com questões sobre a biografia dos sujeitos, nível de formação profissional, tempo e nível de experiência pessoal no ensino inclusivo. A entrevista semiestruturada permitiu a obtenção de descrições das professores sobre suas percepções a respeito das dificuldades metodológicas, contextuais e de conteúdos para a implementação do ensino inclusivo. Os dados foram tratados com a técnica de análise de conteúdo com categorias determinadas a priori. Os resultados indicam o predomínio de dificuldades em relação às estruturas físicas e recursos materiais para as aulas; para promover variabilidade e estabelecer uma sequência aos conteúdos, e ainda para a seleção e utilização de estratégias que favoreçam a prática cooperativa entre os alunos.

Palavras-Chave: Educação especial; Educação Física; Professor; Inclusão.

\section{THE INCLUSIVE EDUCATION IN PHYSICAL EDUCATION CLASSES: A STUDY FROM THE PERCEPTION OF TEACHERS}

\begin{abstract}
The aim of the study was to describe the teacher's perceptions in regarding the difficulties to implement inclusive education in regular physical education classes. It has been conducted a qualitative study with three Physical Education teachers. To collect the data it has been used a structured interview guide with questions about the subject's biography, level of training, time and level of personal experience in inclusive education. A semistructured interview allowed to obtain teacher's descriptions about their perceptions regarding the methodological, contextual and content difficulties for the implementation of inclusive education. The data were treated with the technique of content analysis with Conexões: revista da Faculdade de Educação Física da UNICAMP, Campinas, v. 13, n. 3, p. 24-47, jul./set. 2015. ISSN: 1983-9030
\end{abstract}


categories determined previously. The results have indicated the prevalence of difficulties in relation to physical structures and resource materials for classes; to promote and establish sequence variability of the contents, and for the selection and use of strategies that foster cooperative practice among students.

Key-Words: Special education; Physical Education; Teacher; Inclusion.

\section{LA EDUCACIÓN INCLUSIVA EN ESCUELAS DE EDUCACIÓN FÍSICA: ESTUDIO DE LA PERCEPCIÓN DE LOS MAESTROS}

\section{RESUMEN}

El objetivo del estudio fue describir la percepción de los profesores, sobre las dificultades para poner en práctica la educación inclusiva en las clases regulares de Educación física. Se realizó un estudio cualitativo con tres profesores de Educación Física. Para recoger los datos se utilizó una guía de entrevista estructurada con reguntas sobre la biografía del sujeto, nivel de formación, tiempo y nivel de experiencia personal en la educación inclusiva. Las entrevistas semiestructuradas permitiron obtener descripciones de las percepciones de los profesores a respecto de sus dificultades metodológicas, contextuales y de contenido, para la implementación de la educación inclusiva. Los datos fueron analizados con la técnica de análisis de contenido con ciertas categorías a priori. Los resultados indican que la prevalencia de dificultades relacionadas a las estructuras físicas y de recursos materiales para las clases; para promover variabilidad y establecer una secuencia a los contenidos; y para la selección y utilización de estrategias para favorecer la práctica cooperactiva entre los alumnos.

Palabras-Clave: Educación especial; Educación Física; Maestro; Inclusión. 


\section{INTRODUÇÃO}

A temática da inclusão foi oficialmente inserida nos currículos dos cursos de graduação em Educação Física, a partir da Resolução no 03/1987 do Conselho Federal de Educação. As alterações provenientes da legislação, têm gerado preocupações quanto à intervenção dos futuros profissionais de Educação Física, na implementação de uma prática pedagógica que atenda as diversidades sociais e humanas, promovendo, de fato, a participação e aprendizagem dos alunos, sem distinção. ${ }^{1-2}$

Os principais desafios para o ensino inclusivo têm sido as atitudes docentes frente à diversidade das características dos alunos no contexto escolar, a adequação dos espaços físicos disponíveis, os tipos de conteúdos que contemplem e valorizem as diferenças individuais e, as estratégias de ensino que criem melhores condições de aprendizagem dos alunos. $^{3-5}$

De acordo com Briant e Oliver, ${ }^{6}$ a formação docente para o ensino inclusivo, bem como a falta de preparo para viabilizar a aprendizagem e participação de alunos com necessidades educacionais especiais tem sido foco de estudos nesta área, a exemplo as investigações de Beyer, ${ }^{7}$ Hummel, ${ }^{8}$ Martins, ${ }^{9}$ Vitaliano. ${ }^{10}$ Em particular, o destaque são as temáticas relacionadas à fragilidade dos currículos dos cursos de formação inicial dos professores e as competências docentes para promover um ensino inclusivo efetivo. ${ }^{11}$

De modo geral, a literatura indica o despreparo dos professores para diante desta realidade atual do ensino e também a ausência de uma rede de apoio para se promover um ensino inclusivo efetivo ${ }^{6}$ No âmbito da Educação Física, os resultados relativos à intervenção pedagógica mostram que os professores se percebem despreparados para realizar a inclusão nas aulas do ensino regular, e têm desenvolvido atividades de aula com uma abordagem "aplicacionista", que consiste primordialmente, na necessidade do domínio de conhecimentos teóricos para serem adaptados ou aplicados no ambiente de prática pedagógica. $\mathrm{O}$ professor, nesta perspectiva, assume a função de técnico especialista, a quem cabe apenas selecionar as metodologias e técnicas de ensino mais adequadas, para poder aplicar os conhecimentos teóricos disponibilizados por especialistas de outras áreas científicas. ${ }^{12-15}$ 
As consequências deste entendimento na atividade do professor remetem ao fato de que apenas o conhecimento comprovado científicamente e proveniente de investigadores e instituições universitárias, em sua maioria, servem como suporte à prática docente. Criando uma dicotomia entre conhecimento teórico e prático, superior e inferior. Contudo, a natureza descontextualizada destes conhecimentos científicos, disponibilizados nos cursos de formação, não parece resolver os problemas do cotidiano da prática que demandam um conjunto de conhecimentos pedagógicos específicos e situados, comprometendo ainda mais a percepção de competência que o professor tem de si mesmo.

De fato, a insegurança e as crenças dos professores a respeito da falta de conhecimentos necessários para atuar com as diferenças individuais nas aulas, têm mantido a Educação Física ainda à margem do movimento da inclusão, à medida que em grande parte, os alunos com deficiências tendem ou são dispensados das aulas. ${ }^{16}$

Para além de uma falta de participação de todos os alunos nas atividades rotineiras, as práticas pedagógicas equivocadas, sob o ponto de vista da inclusão, têm levado a uma dificuldade dos alunos com deficiência integrarem-se aos demais, há uma falta de prática conjunta de todos os alunos e dos próprios alunos com deficiência, por não reconhecerem suas próprias possibilidades de ação. ${ }^{17}$

Nesta perspectiva, Briant e Oliver $^{6}$ salientam que as políticas, as ações, as dificuldades percebidas pela comunidade escolar no dia-dia da escola, devem receber destacada atenção nos estudos da área. O interesse, de fato, é na possibilidade de redefinir as estratégias e ações para a inclusão no contexto escolar, a fim de facilitar o acesso e a permanência dos alunos com deficiência, no ensino regular.

Portanto, tendo como referência a reestruturação do ensino regular e as consequências destas mudanças na intervenção dos professores de Educação Física e ainda, a necessidade de investigações que aborde dilemas cotidianos do professor de Educação Física na promoção do ensino inclusivo, ${ }^{13}$ esta pesquisa tem como objetivo descrever a forma como os professores percebem a sua prática pedagógica, em particular, as dificuldades para implementar o ensino inclusivo nas aulas regulares de Educação Física. Conexões: revista da Faculdade de Educação Física da UNICAMP, Campinas, v. 13, n. 3, p. 24-47, jul./set. 2015. ISSN: $1983-9030$ 


\section{MÉTODO}

Neste estudo, adotou-se um delineamento de pesquisa qualitativa, uma denominação que abrange procedimentos em que o investigador recolhe as informações de forma direta, seguindo uma análise indutiva dos dados. ${ }^{18}$ A delimitação do estudo a um único contexto educativo (escola) pode ainda caracterizá-lo como um estudo de caso, conforme Thomas e Nelson. ${ }^{19}$ Utilizou-se, também, procedimento de pesquisa estudo de casos múltiplos, na qual cada sujeito é descrito individualmente e confrontados entre si, conforme Yin. ${ }^{20}$

\section{Sujeitos da pesquisa}

Para a seleção dos sujeitos, adotaram-se os seguintes critérios: a) Estar atuando como professor de Educação Física escolar, com alunos com deficiências na classe regular; b) expressar motivação e disponibilidade para participar do estudo.

Foram investigadas todos os professores de Educação Física (total de 3), que no período do estudo atuavam em uma escola importante, da região central de Florianópolis (número de alunos, estrutura física e de humanos e pedagógicos), da rede pública de ensino do Estado de Santa Catarina. A escolha dos professores investigados e da escola ocorreu de forma intencional, em virtude de um dos investigadores estar atuando como professor na escola em questão. Desse modo, o investigador obteve a confiança e colaboração espontânea dos sujeitos para realizar a pesquisa, que no caso de pesquisa qualitativa com algum caráter especulativo, apresenta-se como um fator importante para obter as respostas mais autênticas. Ainda, a escola, em virtude de sua importância, é uma das quais acolhe o Programa de Professor de Apoio, que consiste na disponibilização de um profissional de apoio especializado para atendimento aos alunos com necessidades educacionais especiais no ensino de base.

Assim, o professor 1 (P1) possuía 27 anos de idade, graduada em Educação Física desde 2006, com especialização em fisiologia do exercício. P1 lecionava há 6 anos para séries inicias do Ensino Fundamental ( $1^{\circ}$ ao $5^{\circ}$ ano) e a 5 anos atuava com alunos com deficiência. Com 23 anos de idade, o professor 2 (P2) concluiu sua graduação em Educação Física em 
2012. Atuava com alunos do $6^{\circ}$ ao $9^{\circ}$ ano do Ensino Fundamental. O professor 3 (P3) possuía 23 anos de idade, licenciada em Educação Física desde 2011 e especialista em gestão educacional desde 2012, P3 atuava há 1 ano como professor para alunos do Ensino Médio da escola. No período da pesquisa todos os professores (P1, P2 e P3) possuíam, em suas aulas, alunos com deficiência física e intelectual, indicando que a maior frequência de indivíduos nas aulas era com necessidades especiais intelectuais. Todas indicaram obter conhecimentos sobre a inclusão nos cursos de graduação. As fontes de conhecimento mais utilizadas para auxiliar nas aulas foram a observação e conversa com colegas, reflexão de sua prática e internet.

\section{Instrumentos de coleta dos dados}

Os dados foram coletados a partir de um roteiro de entrevista estruturada ${ }^{21}$ e um roteiro de entrevista semiestruturada. O inquérito estruturado foi composto de 20 questões que buscaram abranger informações sobre a biografia dos sujeitos; nível de formação profissional; tempo e nível de experiência pessoal no ensino inclusivo.

As 19 questões que compuseram a entrevista semiestruturada permitiram a obtenção de descrições dos professores sobre suas percepções a respeito das dificuldades metodológicas, contextuais e de conteúdos para a implementação do ensino inclusivo. Nas entrevistas, a formulação e ordem das questões foram previamente estabelecidas, mas permitiram tanto aos investigados fornecerem respostas longas, quanto ao pesquisador intervir para estimular respostas mais completas sobre a temática, conforme Ghiglione e Matalon. $^{22}$

\section{Procedimentos éticos}

A pesquisa foi aprovada por um comitê de ética em pesquisa com seres humanos, em universidade pública no Brasil Parecer n548566. Para preservar a identidade dos professores, os sujeitos estão identificados no texto por P1, P2, P3. Os mesmos foram informados sobre os objetivos da investigação, aceitaram participar do estudo voluntariamente e assinaram o termo de consentimento livre de participação e de divulgação dos resultados para fins pedagógicos e científicos. 


\section{Procedimentos de coleta de dados}

As respostas emitidas pelos professores foram captadas por meio de gravador digital, em local reservado, com data e horário de conveniência dos sujeitos. As entrevistas tiveram duração média de 75 minutos. As informações foram armazenadas em microcomputador dos pesquisadores e transcritas, literalmente, com o auxílio dos programas Windows Media Player e Word.

\section{Procedimentos de análise dos dados}

No processo de análise utilizou-se a técnica de análise de conteúdo, em conformidade com Bardin. ${ }^{23}$ Este processo consiste em três etapas principais: pré-análise, na qual os dados das entrevistas e transcrições foram organizados; em seguida houve a exploração e codificação dos conteúdos das transcrições, identificando as unidades de significado em função das classes de análise; por fim, na terceira etapa, foram realizadas as contagens da frequência das unidades e organização dos resultados.

As categorias de análise foram determinadas a priori com base na estrutura do conhecimento profissional do professor, proposto por Shulman ${ }^{24-25}$ e Grossman, ${ }^{26}$ particularmente, sobre o conhecimento do contexto, que corresponde ao entendimento do professor sobre seu ambiente de trabalho, região e características culturais da comunidade em que atua; o conhecimento curricular do conteúdo o qual inclui o conhecimento dos recursos disponíveis para estruturar uma determinada matéria para o ensino, assim como o ajustamento desta, o nível de profundidade e a progressão dos conteúdos nos programas de ensino; e ainda, o conhecimento das estratégias de ensino o qual faz referência às formas como o professor realiza o ensino, isto é, como ele representa o conteúdo, os tipos de instrução, demonstrações, explicações, analogias, metáforas, exemplos, tarefas de aprendizagem ou exercícios que o professor utiliza para fazer o aluno compreender um tópico específico do conteúdo. $^{25-27}$

Para conferir a validade descritiva e interpretativa aos dados, foram empregados procedimentos de checagem pelos participantes, que consistiu no envio das descrições aos sujeitos para confirmação da correspondência entre as informações fornecidas nas entrevistas e as descrições realizadas pelos investigadores. ${ }^{28-29}$ 


\section{RESULTADOS}

\section{As dificuldades no contexto das aulas de Educação Física}

Nos resultados a respeito do contexto, os professores citaram alguns elementos que acreditam interferir na inclusão dos alunos com deficiência, no ambiente escolar, em especial, nas suas aulas. São eles, o espaço físico, os materiais e equipamentos disponíveis para aulas, a participação da família no cotidiano escolar, a necessidade de orientação ou apoio educacional específico sobre a temática na escola e o auxílio do segundo professor. Segundo Professor de Turma é uma denominação dada a um profissional da área educação,

[...] preferencialmente habilitado em educação especial, tem por função corrigir a classe com o professor titular, contribuir em função do seu conhecimento específico, com a proposição de procedimentos diferencias para qualificar a prática pedagógica. ${ }^{30}$

Para P1, a estrutura física da escola, os recursos materiais de aula são destacadamente fatores limitadores para o ensino inclusivo, principalmente aos alunos com deficiência física. Os acessos às salas de aula e às duas quadras poliesportivas não são adequados. As dificuldades destacadas por P2 e P3 se assemelham ao professor P1 e recaem sobre as dificuldades de acesso dos alunos com deficiência física às quadras esportivas.

"A Maria (nome fictício de uma aluna com deficiência física), que é cadeirante, tem bastante dificuldade de acesso às quadras. Só dá para ela ir até o ginásio, porque se for para as outras quadras não tem rampa de acesso para ela. Ou, mesmo se ela ficar na sala de Educação Física, naquela areazinha, tem um degrau, não tem uma rampa" (P3).

A ausência de recursos materiais adequados e diversificados para o desenvolvimento das aulas é também destacada por P2 como um fator contextual limitante de sua prática pedagógica, como se verifica no excerto a seguir:

\footnotetext{
"São os materiais, porque quando a gente está na faculdade, à gente tem um mundo de possibilidades. Tudo que tu pensas em planejar e fazer, tu tens a possibilidade, tem os materiais. E, aqui já não é bem assim. Tu tens, na maioria das vezes, que planejar a tua aula de acordo com o que tem ali, para ti e não ao contrário" (P2).
}

Em contrapartida, P1 indica como elementos facilitadores o apoio ou "parceria" com outros professores de Educação Física, à medida que cooperam entre si para disponibilizar as melhores condições de aula, o número de quadras esportivas e ainda, a presença em aula de segundo professor auxiliando na inclusão dos alunos. 
Diferentemente de P1, os professores P2 e P3 acreditam que o "segundo professor" tem uma contribuição restrita em relação às aulas de Educação Física, muito embora sejam importantes no processo de inclusão de um modo geral. Como se verifica no excerto retirado da entrevista de $\mathrm{P} 3$ :

\begin{abstract}
"Trazendo para o lado da Educação Física, se fosse uma pessoa preparada para utilizar esta Educação Física para trabalhar o aluno, realmente eu veria como uma forma positiva. Eu vejo que na sala de aula é de extrema ajuda para os professores de sala, não questiono [...] na Educação Física, não tem um trabalho muito efetivo, acaba ficando mais como um cuidador" (P3).
\end{abstract}

\title{
As dificuldades no ensino dos conteúdos
}

Verificou-se que os conteúdos priorizados por P1 no ensino fundamental ( $1^{\circ}$ ao $5^{\circ}$ ano), são as atividades lúdicas, brincadeiras de roda, brincadeiras cantadas, exercícios ritmados, jogos e esportes. Por sua vez, P2 e P3 indicam ênfase no ensino de modalidades esportivas, em particular o basquetebol, voleibol, handebol, futebol. P2 contempla, ainda, os conhecimentos relacionados à dança e à ginástica.

Para o professor $1(\mathrm{P} 1)$, as dificuldades estão relacionadas à incipiente formação obtida durante sua graduação, agravadas pela falta de informações sobre os alunos e ao pouco conhecimento que possui a respeito de pessoas com deficiência.

"É terrível! Até você conhecer todos eles, porque a gente deveria saber mais sobre eles. Na verdade, tínhamos que ter estas informações continuamente para saber de cada deficiência, cada necessidade, para a gente trabalhar em cima disso" (P1).

Para além das dificuldades geradas pela falta de informação precisa sobre as características dos alunos, P2 indica a resistência dos alunos diante da introdução de novos conteúdos e o interesse na prática do futebol formal, como limitador do processo de inclusão. Para ele, esta situação induz a um tipo de prática competitiva e seletiva que impede a participação dos alunos com deficiência. Especificamente, os alunos com deficiência intelectual.

"O futebol é o principal deles. É tudo um acordo. Para aceitar coisas fora do futebol, já foi complicado. Então, é tudo em acordo, a gente joga um pouquinho desses, depois a gente joga um pouquinho daquele, porque eles estão enraizados com este negócio do futebol, que a gente tem que lutar todos os dias contra isso" (P2).

P3 também indica que preparação insuficiente na formação inicial se reflete na seleção dos conteúdos para as turmas do Ensino Médio. A prática dos esportes coletivos formais ou 
tradicionais é uma constante em suas aulas e dificulta a participação dos alunos com deficiência. A restrição da participação destes alunos nestas práticas se dá pela exigência técnica destas atividades, a complexidade de seu desenvolvimento e a natureza competitiva típica destas modalidades esportivas.

\section{As dificuldades nas estratégias de ensino}

As estratégias indicadas pelos professores para realizar a inclusão nas suas aulas de Educação Física são a reunião de todo os alunos no início da aula para explicitar os objetivos e atividades a serem realizadas; a utilização de jogos e brincadeiras, explorando seu caráter lúdico e possibilidades de participação de todos, de forma simultânea; a realização constantes de orientações (feedback) aos alunos, sem a interrupção das atividades de ensino, com o propósito de manter os alunos atentos e engajados nas mesmas, certificar-se da compreensão e objetivo das atividades, manutenção da motivação e controle das relações sociais entre os próprios alunos; diversificar os tipos de jogos e brincadeiras ampliando suas vivências ou experiências pessoais.

Segundo P1, o nível de deficiência intelectual "leve" verificada na aluna, da turma em que leciona, não interfere de forma significativa no processo de inclusão que busca implementar. Suas maiores dificuldades estão relacionadas à mediação dos conflitos sociais entre os alunos, para que haja compreensão das atividades que propõe.

Para P2, as dificuldades para a inclusão se acentuam na medida em que ela busca interferir na aula para alterar as atividades ou os conteúdos de ensino. Suas iniciativas de introduzir atividades inovadoras, que não sejam a prática formal do futebol, parecem comprometer as relações sociais entre professor e alunos durante o desenvolvimento das aulas. As dificuldades em estabelecer relações sociais entre os alunos com deficiência e os demais, parece também ser um fator que prejudica a inclusão, segundo P2. No caso específico de Flávia (nome fictício de uma aluna com deficiência intelectual), os demais alunos evidenciam alguma rejeição à sua participação nas atividades. Conforme excerto do professor: “[...] Ali, na Flávia, a gente tem que estar sempre fazendo com que os amigos compreendam que ela também quer jogar, que ela vai jogar. Então o trabalho é sempre com 
os outros, para que eles a aceitem dentro do jogo [...]" (P2).

Segundo P2, quando as deficiências se acentuam, como é o caso de outra de suas alunas que possui deficiência intelectual "moderada" com comprometimento motor, este processo de inclusão praticamente não ocorre nas aulas de Educação Física. Nestas circunstâncias, P2 acredita que um trabalho mais integrado e específico (no qual o segundo professor tivesse mais conhecimento específico sobre a Educação Física), entre os professores de Educação Física e o segundo professor, poderia minimizar esta dificuldade.

O professor P3 refere que duas situações de inclusão ocorrem diariamente em suas aulas. A primeira, diz respeito a um aluno com deficiência intelectual e motora. Sua participação nas práticas esportivas é quase sempre obtida a partir de um esforço e uma dedicação intensa do professor, quase individualizada, em estimular tal aluno, monitorar seu comportamento, assim como monitorar os demais para que a prática motora colaborativa ocorra de fato.

\begin{abstract}
"Eu acho que o fato de eu sempre exigir que o Lucas (nome fictício do aluno com deficiência) esteja inserido em um time, facilita bastante. Assim ele se sente parte desse grupo. Então eu oriento para ele ajudar o time a proteger o gol, a cuidar do seu campo e quando a bola vem, ele bota o pé e defende com se aquilo fosse a vida dele. Então eu acho que ele se sente parte do grupo e contribui ainda mais para a relação entre eles. Eu acho que ele se sente também, pelo fato de eu estar sempre incluindo e brigando por ele, tanto é que ele vem perguntar para mim, de que time ele é e, o que eles irão fazer. Ele sabe que eu vou incluí-lo na atividade" (P3).
\end{abstract}

A segunda situação de inclusão indicada por P3 surge da necessidade de inclusão de uma aluna com deficiência física. É nesta circunstância que toda a insegurança, frustração e dificuldades se acentuam, fazendo com que a professor indique, de fato, a falha ou ausência no processo de inclusão escolar.

"Maria (nome fictício de uma aluna com deficiência física) é o caso que mais me frustra hoje, por eu não saber e não conseguir inseri-la nas minhas atividades. Me dói, como professor de Educação Física, eu quero sempre os meus alunos se movimentando, fazendo alguma coisa, participando. Até aqueles que não querem participar. Eu sempre tento saber por que eles não participam. Me dói, ela estar lá com a outra professor olhando a minha aula. Meu Deus! Me frustra muito, eu queria me sentir mais preparada para saber trabalhar bem, conseguir incluí-los bem, de estar tranquila, de dizer: - Ah, eu consigo fazer inclusão nas minhas aulas de Educação Física" (P3).

\title{
DISCUSSÃO
}

Conexões: revista da Faculdade de Educação Física da UNICAMP, Campinas, v. 13, n. 3, p. 24-47, jul./set. 2015. ISSN: 1983-9030 
Todos os professores investigadas indicaram ter recebido preparação para o ensino inclusivo durante a formação inicial. Contudo, esta preparação parece não ter contribuído de maneira significativa para a resolução dos dilemas que se apresentam cotidianamente na prática docente em Educação Física.

Segundo Falkenbach et al., ${ }^{31}$ é comum às estruturas curriculares dos cursos de formação em Educação Física apresentar uma única disciplina, durante todo o curso, que contemple de forma específica temas referentes à intervenção profissional com indivíduos com deficiência. Esta forma limitada de abordar a inclusão nos cursos de graduação pode explicar, em parte, as dificuldades indicados neste estudo.

Em estudo com professores de Educação Física em nível básico, Martins ${ }^{32}$ verificou que na percepção destes profissionais um dos aspectos que mais influenciam as atitudes inclusivas é a formação especializada sobre esta temática, o que para eles, de fato, pode favorecer uma intervenção que responda as necessidades de todos os estudantes da classe. Frente à limitação das estruturas curriculares dos cursos de formação inicial em Educação Física, sobretudo a respeito das estratégias e do nível de profundidade com que a temática da inclusão tem sido tratada, indicam que a formação continuada é considerada pelos professores mais relevante, isto é, que fornece maiores contribuições para a resolução dos dilemas diários presentes nas aulas de Educação Física no contex to inclusivo. ${ }^{33}$

As percepções de despreparo profissional dos professores investigados podem estar associadas, em parte, à Fase da Carreira profissional em que se encontram P1, P2 e P3, por estarem numa Fase de Entrada na carreira, conforme critérios de Nascimento e Graça ${ }^{34}$ razão pela qual, todos os professores indicam inseguranças e se reportam à formação inicial como fonte de conhecimento importante para a inclusão.

A insuficiência de conhecimentos obtidos na formação inicial em Educação Física para estes professores atribui relevância ao modo informal de obtenção de conhecimento útil para o ensino inclusivo. As conversas com seus colegas professores, a busca de informações na internet, a observação de outros professores durante o ensino e a reflexão sobre sua prática, indicam que os conhecimentos pedagógicos que possuem são obtidos de forma autônoma e decorrente de situações de compartilhamento social das informações. ${ }^{35}$ Conexões: revista da Faculdade de Educação Física da UNICAMP, Campinas, v. 13, n. 3, p. 24-47, jul./set. 2015. ISSN: $1983-9030$ 
As dificuldades dos professores para o ensino de alunos com deficiência geram preocupações relacionadas, principalmente, à impossibilidade de cumprir com seus objetivos, de fornecer autonomia e promoção da saúde. Neste processo cabe ao professor de Educação Física encontrar soluções pedagógicas que contemplem as individualidades de todos os alunos, bem como seus interesses. ${ }^{36-37}$

É essencial, portanto, que o professor de Educação Física possua um conjunto de conhecimentos que abranjam os aspectos do desenvolvimento humano, as características de cada deficiência, a origem e consequências dos diversos tipos de deficiências. ${ }^{38-39}$

No caso dos professores investigados, suas dificuldades e inseguranças estão relacionadas à falta de informações sobre seus alunos com deficiência e de conhecimento sobre os tipos de deficiências. Ainda mais, suas propostas pedagógicas em favor da inclusão são comprometidas, também, pela estrutura física e recursos materiais disponíveis para desempenharem suas tarefas profissionais.

De fato, os obstáculos que persistem nas sociedades atuais é ainda uma herança de um mundo pensado e organizado para as pessoas sem deficiência, de modo que a escola, em especial, deve adaptar-se às particularidades de todos os alunos. ${ }^{40}{ }^{40}$ Segundo Mazzarino, Falkenbach e Rissi, ${ }^{41}$ apesar de existirem Leis Federais como a 10.048/2000 que garantem a acessibilidade para todas as pessoas, inclusive no ambiente escolar, alguns estudos, em particular os de Falkenbach et al. ${ }^{42}$ e Santos e Falkenbach, ${ }^{43}$ indicam que as escolas começam a se preocupar com a inclusão e à acessibilidade apenas quando os alunos com deficiência ingressam no ambiente escolar.

Particularmente para P3 e P2, que ensinam alunos com deficiência motora, a falta de acesso ou rampa contínua e sem degraus ligando os demais andares da escola à quadra esportiva, prejudica a participação desses alunos nas aulas. As limitações do espaço físico comprometem diretamente a oportunidade de convívio social, acarretando, quase sempre, ao segregacionismo, à falta de socialização, participação e ao sedentarismo destes alunos. Não é raro, alunos com deficiência apresentarem comportamentos de isolamento diante dos demais, criando dentro de si preconceitos em relação a si e aos outros, difíceis de serem Conexões: revista da Faculdade de Educação Física da UNICAMP, Campinas, v. 13, n. 3, p. 24-47, jul./set. 2015. ISSN: $1983-9030$ 
ultrapassados. $^{4,44}$

Para além das rampas de acesso, outras modificações devem ser realizadas para que a inclusão ocorra de modo efetivo. São necessárias portas com aberturas amplas nas salas de aula, sanitários totalmente adaptados, mobílias com altura e dimensões ajustadas, escadas com corrimão, sinais e indicadores nos ambientes, dentre outros elementos. ${ }^{4,44} \mathrm{Na}$ acessibilidade no ambiente escolar, portanto, deve ser garantida a salas de aula, a espaços destinados ao convívio social dos alunos, a bibliotecas, sala dos professores, secretarias, coordenação, sanitários, refeitórios e também as áreas de práticas esportivas. ${ }^{41}$

A contribuição de um profissional auxiliar, no apoio às aulas de Educação Física, não parece ser um ponto de consenso entre os professores investigados. No caso de P2 e P3, a contribuição nas aulas é insuficiente. Porém, reconhecem a importância deste segundo professor no processo de inclusão escolar, de um modo geral. Por outro lado, para P1 a participação do segundo professor tem se efetivado como um agente facilitador da inclusão nas aulas de Educação Física.

De acordo com Briant e Oliver, ${ }^{6}$ é fundamental que o professor conte com o auxilio de uma equipe de apoio na escola, a qual pode ser composta por diferentes profissionais do campo da educação, da área da saúde, como os terapeutas ocupacionais, por meio do trabalho de apoio direto ou indireto ao professor, à família, à comunidade escolar e também à criança. Além disso, o auxilio de um professor especialista no ensino de crianças com diferentes tipos de deficiência e um psicólogo educacional, em horário contrário ao do ensino regular, também podem fazer parte de uma política educacional de inclusão. ${ }^{6,32}$

A falta de conhecimento sobre os alunos, relatada pelos professores investigados, repercute na seleção inadequada dos conteúdos, na impossibilidade de se estabelecer uma sequência destes conteúdos, seu grau de profundidade e a forma mais adequada de ajustar o conteúdo que se pretende ensinar, a um nível de compreensão e possibilidade de execução do aluno. Segundo Sassaki, ${ }^{5}$ a falta de conhecimentos sobre os alunos e de suas necessidades, interferem significativamente e de forma negativa na estruturação curricular do professor. As consequências diretas para os alunos com deficiência, podem ser o sentimento de fracasso, a falta de motivação para a prática. Ademais, deve-se considerar que esta falta de Conexões: revista da Faculdade de Educação Física da UNICAMP, Campinas, v. 13, n. 3, p. 24-47, jul./set. 2015. ISSN: $1983-9030$ 
conhecimento pode ir além de um processo de inclusão com falhas, ou a exclusão dos alunos com deficiência, podendo inclusive, gerar prejuízos graves para os alunos, dependendo da deficiência que apresentam.

Outra situação que agrava as dificuldades dos professores a respeito dos conteúdos da Educação Física é a resistência que a maioria dos alunos apresenta para manter a prática do futebol durante as aulas. De acordo com Aguiar e Duarte ${ }^{45}$ a cultura esportiva, ainda preponderante em muitas propostas curriculares em Educação Física, não favorece os valores de cooperação e inclusão. Ao contrário, os valores competitivos inerentes a esta cultura podem criar resistência à inclusão, à medida que os alunos com deficiência são interpretados como menos capazes para se obter êxito e superar o adversário. A prática esportiva, quando usada nos moldes formais, sem considerar os valores da inclusão, pode se constituir em uma fonte de exclusão e uma barreira à educação inclusiva.

Segundo Martins, ${ }^{32}$ além das características tradicionais deste componente curricular favorecer a exclusão de alguns alunos, ao priorizar a competição e o desempenho; os profissionais da Educação Física ainda encontram inúmeras dificuldades em desenvolver ações pedagógicas que atendam realidade social heterogênea. Historicamente, as aulas de Educação Física se configuraram como uma situação de destacarem quem possui condições ou não de realizar práticas esportivas seja através das dispensas históricas da Educação Física, ou através do caráter seletivo e excludente das estratégias selecionadas pelo professor. ${ }^{41-42,46}$

Realizar a inclusão nas aulas de Educação Física implica encontrar soluções pedagógicas para que o nível de dificuldade avance continuamente, sem que o aluno fique receoso de um possível fracasso. Sendo importante também que o professor proponha atividades condizentes com a personalidade dos alunos, a motivação e ao momento da aula, proporcionando a experimentação de diferentes atividades. ${ }^{37}$

Ademais, a diversidade de alunos em aula, pela presença de crianças com e sem deficiências, pode ser interpretada como um fator motivante à adoção de estratégias que criem um ambiente educativo mais rico para todos. Objetivamente, as mudanças metodológicas e de gestão das aulas passam a atender as necessidades dos alunos que apresentam dificuldades, mas podem beneficiar todos os demais alunos da classe. ${ }^{6}$ Conexões: revista da Faculdade de Educação Física da UNICAMP, Campinas, v. 13, n. 3, p. 24-47, jul./set. 2015. ISSN: $1983-9030$ 
Para Siedentop, ${ }^{47}$ as estratégias que tornam o processo de ensino-aprendizagem mais eficaz, podem ser caracterizados e interpretados a partir de três sistemas de tarefas. Os três elementos interagem entre si, de modo que qualquer modificação em um deles provoca um desequilíbrio nos demais. As tarefas são denominadas: tarefas de organização da aula; tarefas de interação social entre os participantes da aula (professor/aluno/aluno) e tarefas de aprendizagem, ligadas diretamente aos conteúdos de ensino.

No caso dos professores investigados, a prática do futebol praticamente determina e impõe uma forma de organização da aula. Ou seja, toda a sua aula apresenta uma organização semelhante ao jogo formal do futebol. As equipes são formadas, há o inicio do jogo, duas equipes se confrontam, há o intervalo de jogo e o fim do jogo, que se equivale ao fim da aula. A aula de Educação Física, quando observada nestas circunstâncias, particularmente para P2 e P3 apresenta-se organizada de acordo com as características de uma partida de futebol, em vez de uma rotina de aula, ajustada às características dos alunos.

A aula organizada deste modo parece interferir negativamente nas tarefas de relações sociais destes professores (P2, P3). A tentativa delas de intervir e solicitar a mudança da estrutura da aula ou mesmo da atividade esportiva não é bem recebida pelos alunos, provocando relação de conflito entre professor e alunos. Para P1 as dificuldades relativas às tarefas de relações sociais dizem respeito aos conflitos entre os próprios alunos durante a aula. Como sugere Falkenback et. al, ${ }^{31}$ enquanto a prática pedagógica nas aulas de Educação Física estiver centrada no movimento e no desenvolvimento da técnica, fundamentadas, ainda, em valores de melhor ou pior, certo ou errado e ganhar ou perder, sempre haverá margem para a exclusão.

Contudo, não existe um método ideal a ser utilizado nas aulas de Educação Física que se aplique a proposta da inclusão, cabendo ao professor realizar ajustes e organizações dos alunos e do contexto de aula que permita a remoção das barreiras e a promoção da aprendizagem. ${ }^{38}$ No caso das aulas em que a prática dos esportes prevalece, com sua estrutura pré-estabelecida, fica comprometida a tarefa do professor de realizar os ajustes e modificações necessárias para o atendimento das necessidades dos alunos, portanto, reduzse a possibilidade do professor propor formas de organização dos alunos e do contexto de aula para que os alunos realizem práticas em grupos, práticas individuais ou mesmo Conexões: revista da Faculdade de Educação Física da UNICAMP, Campinas, v. 13, n. 3, p. 24-47, jul./set. 2015. ISSN: $1983-9030$ 
atividades em que todo o grupo esteja completamente envolvido em um objetivo comum, como verificamos em formas de atividades como os jogos cooperativos.

O que se verifica no estudo com estes professores é o fato de que os esforços dos professores em buscar alternativas pedagógicas e estratégias ajustadas às necessidades dos alunos encontram barreiras nas tarefas de organização da aula, nas tarefas de relações sociais com implicações importantes para a aprendizagem dos conteúdos. Estas dificuldades também têm sido indicadas por professores investigados recentemente, a exemplo os estudos de Martins ${ }^{32}$ e Mazzarino, Falkenbach e Rissi. ${ }^{41}$

A falta de apoio pedagógico realizado por uma equipe especializada; a carência de materiais didáticos; e ainda as insuficiências na formação docente foram aspectos citados com maior frequência nos estudos realizados entre 2000 e 2010 a respeito das dificuldades vivenciadas por professores do ensino regular. ${ }^{48}$ De fato, o despreparo pedagógico e falta de estrutura tem atribuído ao professor o papel de professor-cuidador, o que reflete na sobrecarga laboral e consequentemente, na qualidade do processo de ensino e aprendizagem. $^{49}$

Apesar dos professores enfatizarem alguns aspectos em particular, entende-se que a inclusão efetiva se dá a partir da combinação de diversos elementos, nomeadamente, a formação específica na área, apoio especializado, infraestrutura adequada, metodologias que favoreçam a inclusão, etc. Diante disso, Martins ${ }^{32}$ alerta para a utilização de estratégias que podem contribuir na inclusão plena de alunos com deficiência, bem como contribuir na prática pedagógica do professor de Educação Física: adequações na estrutura e funcionamento das escolas, a colaboração de técnicos especializados, a diferenciação pedagógica, a individualização dos percursos de formação adequados às necessidades dos estudantes com Necessidades Especiais.

\section{CONCLUSÃO}

Os professores investigadas encontram-se numa fase inicial da carreira docente, período em que são comuns as sensações de insegurança e despreparo para realizar as tarefas educacionais, sobretudo no processo de ensino inclusivo. 
As situações informais de aprendizagem de caráter social, nomeadamente as conversas com os seus pares, observação de outros professores a ensinar e a internet, tem sido úteis na busca de novos conhecimentos para o ensino.

As barreiras estruturais físicas parecem persistir e influenciar negativamente no processo de inclusão educacional. As estruturas escolares, de modo geral, não apresentam modificações e ajustamentos aos alunos de inclusão, interferindo no processo de convívio dos alunos. Os espaços e equipamentos disponíveis para o desenvolvimento das aulas de Educação Física não se diferem dos espaços tradicionais destinados a esta disciplina. Além disso, a contribuição do segundo professor ou professor auxiliar no apoio a inclusão, nas aulas de Educação Física, não parece ser um ponto de consenso entre os professores investigados.

Selecionar e organizar os conteúdos, adequadamente, adaptadas às necessidades e particularidades dos alunos com deficiência foram apontados como dificuldades fundamentais enfrentadas. Na prática, isto implica na falta de variabilidade, sequência e profundidade de abordagem dos conteúdos, predominantemente decorrem de fatores de gestão escolar e valores culturais ligados ao interesse dos alunos e à pratica do esporte formal.

Os professores apresentam dificuldades em utilizar estratégias de ensino que favoreçam a prática cooperativa e de interação entre os alunos. A cultura esportiva formal, a falta de recursos materiais específicos, os conflitos sociais em aula, a falta de conhecimentos sobre os alunos com deficiência e sobre as características de cada deficiência encontrada, são condições determinantes para que as estratégias de ensino não sejam suficientemente ajustadas às diferenças e particularidades dos alunos com deficiência.

Após o levantamento das dificuldades dos professores verifica-se que os ajustes e direcionamentos políticos administrativos são insuficientes para garantir uma prática pedagógica inclusiva. Acredita-se na importância da realização de mais estudos que contemplem a variabilidade e particularidade de cada contexto, seja regional, escolar ou de aula.

Conexões: revista da Faculdade de Educação Física da UNICAMP, Campinas, v. 13, n. 3, p. 24-47, jul./set. 2015. ISSN: $1983-9030$ 
É necessário que se analise também as possíveis consequências das práticas pedagógicas nos alunos em processo de inclusão escolar. Além disso, reconhecendo a importância que vem sendo atribuída ao segundo professor em aula, parece relevante investigar as políticas para a presença deste profissional, os conhecimentos destes professores, e ainda, sua prática pedagógica para a inclusão. Para tanto será necessário utilizar metodologias de pesquisa para observar a prática do professor, a percepção e evolução das aprendizagens e competências dos alunos.

\section{REFERÊNCIAS}

'OMOTE, S. Mudança de atitudes sociais em relação à inclusão. Paidéia, Ribeirão Preto, v. 32 , n. 15 , p. $387-398,2005$.

${ }^{2}$ RODRIGUES, D.; LIMA-RODRIGUES, L. Formação de Professores e Inclusão: como se reformam os reformadores? Educar em Revista, Curitiba, n. 41, p. 41-60, jul./set. 2011.

${ }^{3}$ GORGATTI, M. G. Educação Física escolar e inclusão: uma análise a partir do desenvolvimento motor e social de adolescentes com deficiência visual e das atitudes dos professores. 2005. Tese (Doutorado em Educação Física) - Universidade de São Paulo, São Paulo, 2005.

${ }^{4}$ SANTOS, C. S. Acessibilidade urbana, escolar e esportiva. In: FERREIRA, E. L. (Org.). Atividade física, deficiência e inclusão escolar. Niterói: Intertexto, 2010. v. 4. p.13-48.

${ }^{5}$ SASSAKI, R. K. Educação Inclusiva: princípios, parâmetros, premissas e procedimentos. In: FERREIRA, E. L. (org.). Atividades físicas inclusivas para pessoas com deficiência. 2. ed. Niterói: Intertexto, 2011a. v.1. p.197-227.

${ }^{6}$ BRIANT, M. E. P.; OLIVER, F. C. Inclusão de crianças com deficiência na escola regular numa região do município de São Paulo: conhecendo estratégias e ações. Revista Brasileira Educação Especial, Marília, v.18, n.1, p. 141-154, 2012. 
${ }^{7}$ BEYER, H. O. A educação inclusiva: incompletudes escolares e perspectivas de ação. Cadernos de Educação Especial, Santa Maria, n. 22, p. 5, 2003.

${ }^{8}$ HUMMEL, E. I. A formação de professores para o uso da informática no processo de ensino e aprendizagem de alunos com necessidades educacionais especiais em classe comum. 2007. Dissertação (Mestrado em Educação) - Universidade Estadual de Londrina, Londrina, 2007.

${ }^{9}$ MARTINS, L. A. R. Inclusão escolar: algumas notas introdutórias. In: MARTINS, L. A. R. et al. (Org.). Inclusão: compartilhando saberes. Petrópolis: Vozes, 2006.

${ }^{10}$ VITALIANO, C. R. Análise da necessidade de preparação pedagógica de professores de cursos de licenciatura para inclusão de alunos com necessidades educacionais especiais. Revista Brasileira de Educação, Marília, v.13, n. 3, p. 399-414, 2007.

${ }^{11}$ FALKENBACH, A. P.; BATTISTELLI, G.; ELOY, D. C. Inclusão e necessidades especiais na produção de conhecimento da Educação Física. In: FALKENBACH, A. P.; BATTISTELLI, G.; ELOY, D. C. Inclusão: perspectivas para as áreas da Educação Física, Saúde e Educação. Várzea Paulista: Fontoura, 2010. p. 152.

${ }^{12}$ CRUZ, G. C. ; OLIVEIRA, J. M. Educação física, escola e inclusão: como avaliar essa relação?. In: FINCK, S. C. M. (Org.). Educação física escolar: saberes, práticas pedagógicas e formação. Curitiba: Inter Saberes, 2013. p. 208-228.

${ }^{13}$ CRUZ, G. C. Práticas e reflexões pedagógicas no contexto da inclusão escolar: contribuições da educação física. In: CHICON, J. F.; RODRIGUES, G. M. Práticas pedagógicas e pesquisa em educação física escolar inclusiva. Vitória: EDUFES, 2012. p. 39-60.

${ }^{14}$ CRUZ, G. C.; SORIANO, J. B. Perspectivas docentes sobre formação profissional em educação física para atuação em contextos inclusivos. Pensar a Prática, Goiânia, v. 13, n. 3, p. 1-16, 2010. 
${ }^{15}$ SILVA, C. S.; SOUZA NETO, S.; DRIGO, A. J. Os professores de Educação Física Adaptada e os saberes docentes. Motriz, Rio Claro, v. 15, n. 3, p. 481-492, 2009.

${ }^{16}$ FREITAS, J. F.; ARAÚJO, P. F. Inclusão escolar e Educação Física: a participação dos professores de Hortôlandia - SP. Pensar a Prática, Goiânia, v. 17, n. 1, p. 01-294, 2014.

${ }^{17}$ FREITAS, R. F. S.; ARAUJO, P. F.; ALMEIDA, J. J. G. O fazer do professor de Educação Física no ensino regular e a inclusão. Lecturas, Educación Física y Deporte, ano 10, n. 72, 2004.

${ }^{18}$ BOGDAN, R.; BIKLEN,S. Investigação qualitativa em educação: uma introdução à teorias e métodos. Porto: Porto, 1994.

${ }^{19}$ THOMAS, J. R.; NELSON, J. K. Research methods in physical activity. 2. ed. Champaign: Human Kinetics, 1990.

${ }^{20}$ YIN, R. K. Estudo de caso: planejamento e métodos. 2. ed. Porto Alegre: Bookman, 2001.

${ }^{21}$ GIL, A. C. Métodos e técnicas de pesquisa social. São Paulo: Atlas, 1995.

${ }^{22}$ GHIGLIONE, R.; MATALON, B. O inquérito: teoria e prática. Oeiras: Celta Editora, 1997.

${ }^{23}$ BARDIN, L. Análise de conteúdo. Lisboa: Edições 70, 1979.

${ }^{24}$ SHULMAN, L. S. Those who understands: knowledge growth in teaching. Educational Researcher, Washington, v.15, n. 2, p. 4-14, 1986.

${ }^{25}$ SHULMAN, L. Knowledge and teaching: foundations of the new reform. Harvard Educational Review, v. 57, p. 1-27, 1987.

${ }^{26}$ GROSSMAN, P. L. The making of a teacher: teacher knowledge and teacher education. Conexões: revista da Faculdade de Educação Física da UNICAMP, Campinas, v. 13, n. 3, p. 24-47, jul./set. 2015. ISSN: 1983-9030 
New York: Teachers College, 1990.

${ }^{27}$ GRAÇA, A. (Ed.). Educação física e desporto na escola: novos desafios, diferentes soluções. Porto: FCDEF/UP, 2001. p.107-20.

${ }^{28}$ ALVES, F. C. A triangulação enquanto técnica de validação qualitativa. Revista Portuguesa de Pedagogia, Coimbra, v. 36, n. 1/3, p. 77-87, 2002.

${ }^{29}$ YIN, R. K. Estudo de caso: planejamento e métodos. 2. ed. Porto Alegre: Bookman, 2001.

${ }^{30}$ SANTA CATARINA. Secretaria de Estado da Educação. Fundação Catarinense de Educação Especial. Programa pedagógico. São José, 2009.

${ }^{31}$ FALKENBACH, A. P. et al. A Inclusão de crianças com necessidades especiais nas aulas de Educação Física na educação infantil. Movimento, Porto Alegre; v. 13, n. 2, p. 37-53, 2007.

${ }^{32}$ MARTINS, C. L. R. Educação Física inclusiva: atitudes dos docentes. Movimento, Porto Alegre, v. 20, n. 2, p. 637-657, 2014.

${ }^{33}$ NASCIMENTO, K. P. et al. A formação do professor de Educação Física na atuação profissional inclusiva. Revista Mackenzie de Educação Física e Esporte, São Paulo, v. 6, n. 3. 2009.

${ }^{34}$ NASCIMENTO, J. V.; GRAÇA, A. A evolução da percepção de competência profissional de professores de Educação Física ao longo da sua carreira docente. In: CONGRESSO DE EDUCAÇÃO FÍSICA E CIÊNCIAS DO DESPORTO DOS PAÍSES DA LÍNGUA PORTUGUESA,6., 1998, Galícia. Acta... Galícia: INEF, 1998.

${ }^{35}$ GARCIA, C. M. Formação de professores: para uma mudança educativa. Porto: Porto, 1999. 
${ }^{36}$ BERSCH, R.; MACHADO, R. Conhecendo o aluno com deficiência. In: BERSCH, R.; MACHADO, R. Atendimento educacional especializado: deficiência física. Brasília: SESP/SEED/MEC, 2007. p.15-24.

${ }^{37}$ VIEIRA, I. B. Atividades e esportes inclusivos para pessoas com deficiência física. In: FERREIRA, E. L.(Org.). Atividades físicas inclusivas para pessoas com deficiência. 2. ed. Niterói: Intertexto, 2011. v. 4, p. 59-118.

${ }^{38}$ CIDADE, R. E.; FREITAS, P. S. Educação Física e inclusão: considerações para a prática pedagógica na escola. Revista Integração, edição especial, p. 27-30, 2002.

${ }^{39}$ LOPES, A. W. A.; VALDÉS, M. T. M. Formação de professores de Educação Física que atuam com alunos com necessidades educacionais especiais (deficiência auditiva): uma experiência no ensino fundamental da rede pública de Fortaleza. Revista Brasileira de Educação Especial, Marília, v. 9, n. 2, p. 195-210, 2003.

${ }^{40}$ MANTOAN, M. T. E. Inclusão escolar: o que é? por quê? como fazer? São Paulo: Moderna, 2003.

${ }^{41}$ MAZZARINO, J. M.; FALKENBACH, A.; RISSI, S. Acessibilidade e inclusão de uma aluna com deficiência visual na escola e na Educação Física. Revista Brasileira de Ciências e Esporte, Florianópolis, v. 33, n. 1, p. 87-102, 2011.

${ }^{42}$ FALKENBACH, A. P. et al. A formação e a prática vivenciada dos professores de educação física com a inclusão de crianças com necessidades educacionais especiais na escola comum. Temas sobre Desenvolvimento, São Paulo, v. 16, p. 56-60, maio 2008b.

${ }^{43}$ SANTOS, H. G.; FALKENBACH, A. P. Aprendizagem e desenvolvimento da criança com deficiência visual: os processos compensatórios de Vygotski. Lecturas Educación Física y Deportes, Buenos Aires, v. 122, p. 1-7, jul. 2008.

${ }^{44}$ RESENDE, N.M. Políticas públicas e acessibilidade dos portadores de deficiência física à educação: ser de direito e estar ao alcance. 2001. Trabalho de Conclusão de Curso Conexões: revista da Faculdade de Educação Física da UNICAMP, Campinas, v. 13, n. 3, p. 24-47, jul./set. 2015. ISSN: 1983-9030 
(Graduação) - Universidade Estadual de Campinas, Campinas, 2001.

${ }^{45}$ AGUIAR, J. S.; DUARTE, E. Educação inclusiva: um estudo na área da educação física. Revista Brasileira de Educação Especial, Marília, v. 11, n. 2, p. 223-240, jul. 2005.

${ }^{46}$ SANTIN, S. Educação Física: da alegria do lúdico à opressão do rendimento. Porto Alegre: EST, 2001.

${ }^{47}$ SIEDENTOP, D. Aprender a enseñar la Educación Física. Barcelona: INDE, 1998.

${ }^{48}$ SILVEIRA, K. A.; ENUMO, S. R. F.; ROSA, E. M. Concepções de professores sobre inclusão escolar e interações em ambiente inclusivo: uma revisão de literatura. Revista Brasileira de Educação Especial, Marília, v. 18, n. 4, p. 695-708, out./dez. 2012.

${ }^{49}$ MELO, F. R. L. V.; FERREIRA, C. C. A. O cuidar do aluno com deficiência física na educação infantil sob a ótica das professoras. Revista Brasileira de Educação Especial, Marília, v.15, n.1, p.121-140, jan./abr. 2009.

Recebido em: 15 jan. 2015

Aceito em: 20 ago. 2015

Contato: emanuellibarros@hotmail.com 